\title{
Refractory Lymphocyte-Rich Classic Hodgkin Lymphoma
}

National Cancer Institute

\section{Source}

National Cancer Institute. Refractory Lymphocyte-Rich Classic Hodgkin Lymphoma. NCI

Thesaurus. Code C142982.

Lymphocyte-rich classic Hodgkin lymphoma that does not respond to treatment. 